\title{
The H1N1 Virus and Mexican Baseball Attendance
}

\author{
By Seth R. Gitter*
}

\begin{abstract}
In 2009 the H1N1 virus severely affected many Mexican industries and decreased total GDP by as much as $0.5 \%$ according to some estimates. This study examines the relationship between the outbreak and social gathering. Using data from the Mexican National Health Service and Mexican League baseball game we find that the H1N1 outbreak reduced baseball game attendance by 15$30 \%$ with a greater reduction in attendance where there were more reports of influenza-like illness. Furthermore, when the Mexican government used moderate social distancing measures that discouraged public gatherings, such as attending a baseball game, attendance declined an additional $20 \%$ controlling for the current infection reports.
\end{abstract}

Keywords: H1N1, Mexico, Baseball, Social Distancing.

\section{Introduction}

In May 2016, a group of 150 public health experts wrote an open letter to the World Health Organization (WHO) urging the postponement of the 2016 Summer Olympic Games in Rio de Janeiro out of concern for the potential to increase the spread of the Zika virus (Sun 2016). Sporting events with high attendance have the potential to spread an outbreak. The WHO and public health officials have had mixed success using public health warnings to reduce large gatherings during outbreaks such as the Severe Acute Respiratory Syndrome (SARS) in 2003 and H1N1influenza in 2009. The economic implications for these outbreaks are large, as Dixon et al (2009) estimate that a pandemic of 60 million flu infections in the US would decrease GDP by nearly $3 \%$ in one year.

In April 2003, the WHO recommended the cancellation of non-essential travel to Toronto due to an outbreak of SARS, though despite this warning sporting events continued. Officials from the Toronto Blue Jays baseball team reported losing 10,000 total ticket sales in the first three days of the warning. In response to low demand, the team offered $\$ 1$ CAD tickets (a 90\% discount) and attendance increased 2.5 times compared to the previous three games (USA Today 2003). Reducing ticket prices in response to low demand, however, may not be optimal from a social standpoint when this attendance leads to more cases during an outbreak. Fortunately, the travel advisory in Toronto was lifted shortly after the game, and no major outbreak occurred.

Social distancing measures were more successful in Mexico during the H1N1 outbreak of 2009. In Mexico, the national government cancelled numerous large-scale events, including soccer matches, baseball games and schools during the beginning of the original outbreak of the flu in the spring of 2009, which may have reduced the spread of the virus (Chowell 2011). In the United States in 2009 a limited number of sporting events were cancelled, which were

\footnotetext{
${ }^{*}$ Associate Professor of Economics, Towson University, USA.
} 
associated with reported cases of H1N1 at some universities (Moltz 2009). Although luckily, the virus was never widespread in the United States.

Surprisingly, there has been little research from economists about the relationship between outbreaks and social gatherings, such as sporting events. This paper tests the relationship between attendance and a major outbreak of a communicable disease, the $\mathrm{H} 1 \mathrm{~N} 1$ flu. We hypothesize that attendance at sporting events will decline as infections increase because those in attendance have a greater risk of exposure. Specifically, we test if Mexican states with higher reported levels of $\mathrm{H} 1 \mathrm{~N} 1$ experienced declines in attendance at baseball games. Secondly, we test the effect on attendance of social distancing measures that discouraged attendance. We hypothesize that by discouraging fans from attending games, attendance will be further reduced even after controlling for the size of the outbreak.

Rational consumers may avoid events when flu outbreaks occur to prevent infection. To our knowledge, consumer behavior and outbreaks have only been tested as they relate to tourists. As expected, tourists avoid areas with potential outbreaks. Rassy and Smith (2013) find that Mexico lost 1 million tourists during the H1N1 outbreak. Rosselló et al (2017) et al. estimate using a gravity model that 12 million tourists a year could be added to African countries by eliminating Malaria, Dengue, Yellow Fever and Ebola. Finally, Kuo et al (2009) find that the avian flu was associated with a decrease in tourism to Asian countries with higher infection rates. Our work adds to this literature by testing the gathering of baseball fans. One key difference is by testing baseball attendance we are looking at a group mainly comprised of Mexican locals and not tourists.

The epidemiological literature is well developed and shows that social distancing measures can prevent the spread of flu and other viruses (Chowell et al 2011, Burke 2005, Couborn et al 2009). Chowell et al (2011) estimate that social distancing in Mexico in response to H1N1 reduced the spread of infection by roughly $1 / 3$, which matches results in other contexts (Wu et al 2010, Hens et al 2009). Two works on gatherings in economics support these findings from epidemiology. Markowitz et al (2010) find that higher levels of employment are associated with increased reports of flu symptoms, suggesting that socialization at workplaces increases the spread of the virus. Stoecker et al (2016) show increased mortality from the flu in cities whose team participates in the Super Bowl, though not in the host city.

Policy makers must weigh the costs of decisions to cancel events against the potential benefits of reducing infections. This paper estimates the cost by showing how many fans would have attended games in the face of an outbreak. When comparing the cost and benefits it may be socially optimal to mandate social distancing measures that cancel games or other large events. Alternatively, social distancing measures can discourage rather than ban attendance as they did in Mexico. Our paper also tests how this policy reduces attendance to estimate the impact of the policy.

Our study examines behavior during the H1N1 outbreak in Mexico in 2009 when there were over 100,000 reports of influenza like symptoms and 1,300 
deaths associated with the outbreak (Chowell et al 2011). The paper uses data from the Mexican social security health service, which covers $40 \%$ of the population, to construct daily measures of $\mathrm{H} 1 \mathrm{~N} 1$ outbreaks. We match this data to daily Mexican baseball attendance for 16 teams across 12 states. The lagged number of influenza cases is used to predict team attendance using a team fixed effects regression. Additionally, we test how moderate social distancing measures by the Mexican government influenced attendance.

\section{Data Description}

In late March and early April 2009, a sharp increase in the number of respiratory related hospitalizations and deaths among youth in Mexico began to alarm officials. By April $23^{\text {rd }}$ a novel strain of swine related influenza referred to as H1N1 was confirmed in Mexico City. Over the course of the next year and half over 100,000 Mexicans reported influenza like illness (ILI) to the Mexican Institute for Social Security, which provides health care for over $40 \%$ of the population (Chowell et al 2011). ILI was defined as the "combination of cough, headache, and fever (except for persons over 65 years of age) with one or more of the following symptoms: sore throat, rhinorrhea, arthralgias, myalgia, prostration, thoracic pain, abdominal pain, nasal congestion, diarrhea, and irritability (for infants only)" Chowell et al (2011).Of those with ILI, roughly $30 \%$ were tested for the presence of $\mathrm{H} 1 \mathrm{~N} 1$, with a confirmation of the H1N1 virus in around three-quarters of the tested cases. Of the reported cases there were roughly 1,300 fatalities with half confirmed as $\mathrm{H} 1 \mathrm{~N} 1$.

We use a subset of the data from Chowell et al (2011), which includes daily ILI reports for all states with a Mexican League baseball team during the Mexican baseball season from April through August of 2009. Chowell et al (2011) provide an overview of the three waves of the pandemic that occurred in Mexico; our study covers the first two waves. The first wave (April1 to May 20) and the second wave that followed (May21 to August 1) coincided with the Mexican baseball season. A third wave occurred with Mexican students returning to school in late August of that year, but as the Mexican baseball season finishes their season in the first week of August, we are unable to analyze the third wave.

In response to the first wave the Mexican government adopted social distancing measures and closed schools from April 27 to May 11 (Chowell 2011). No baseball games were played between April 27 and May 5, 2009, when games are typically played 6 days a week. However, five of the typical eight games were played on May 6 and the full schedule resumed on May 7. Mexican schools remained closed through May 11 and the government generally discouraged large public gatherings during this period. Soccer matches scheduled for the weekend of May $9^{\text {th }}$ were held but only at $50 \%$ capacity. Unfortunately, we do not know if baseball teams took any special precautions during the period from May 6 to 11 when school was canceled and baseball games resumed. We consider any game played between May 6 and May 11 to be during the period when moderate social distancing measures were in effect, since during 
this time the government discouraged public gathering and banned some forms such as school attendance. We hypothesize that attendance would likely be reduced during moderate social distancing measures, which is supported by the results of the empirical analysis.

The empirical analysis uses attendance at Mexican League Baseball games as a proxy for social gathering. That is changes in baseball game attendance may reflect the larger community response in terms of changes in attendance at other public events. The advantage of the data set is teams play roughly 6 games a week over the course of the season so there are a greater number of observations than soccer, for example. With each baseball team playing over 50 home games a year (March-July), the typical team draws a few hundred thousand fans annually.

The Mexican League is one of three AAA baseball leagues (the highest minor league level) that are linked to Major League Baseball (MLB). Unlike the Pacific or International league, the other two AAA leagues, teams are not directly affiliated with a MLB team. That is, MLB teams do not provide players to the Mexican League, nor are players directly promoted to the MLB from the Mexican league. The Mexican Baseball League currently has 16 teams that are spread across 12 Mexican states. The level of attendance is roughly equivalent to AA leagues in the US, which is the second highest level of minor league baseball. The data set on team attendance was provided by MLB. It includes attendance at over 5,200 Mexican league games between 2005-2010.

The main variables of interest are game attendance and influenza-like illness cases. The descriptive statistics are shown in Table 1. In all sample years the teams averaged roughly 4,000 fans per game. In 2008 the year before the flu outbreak team attendance averaged 4,600. In 2009 the year of the H1N1 outbreak average attendance fell to 3,400. This could be related to other factors besides the outbreak of H1N1 as real GDP in Mexico declined over 6\% in 2009 in part due to the global financial crisis. Of course, this decline in GDP may be related to the global recession, in addition to the spread of H1N1.

For influenza-like illness reports we use the sum of reports to the National Health Service during the 3-5 days prior to the game at the state level of the home team. This lag accounts for the time information takes to travel between people's perception of the infection rate and the actual infection rate. It is worth noting that we do not have influenza-like symptom reports for years other than 2009, so Table 1 separates descriptive statistics out for 2009, the influenza report variables are recorded as zero for all years other than 2009.

A descriptive comparison of reports of influenza-like illness and attendance is suggestive of a negative relationship between the two. In Table 2 the number of influenza-like illnesses is divided into groups. In the first set we have five groups based on the number of cases. There is a roughly $18 \%$ drop in attendance from the first to second group of ILI reports with a $12 \%$ and $16 \%$ drop from the second to third and third to fourth (highest ILI reports), respectively.

The final three rows of Table 1 examine the moderate social distancing measures during the period in which social gathering was discouraged. Attendance during this time was roughly $10 \%$ lower than any other time in 2009 and a little over 20\% lower than the same period (May 6-11) for all other years. 
Table 1. Descriptive Statistics

\begin{tabular}{|c|c|c|c|c|}
\hline All Years (2005-2010) & Mean & SD & Min & Max \\
\hline Attendance & 3996 & 3304 & 107 & 25773 \\
\hline State Influenza Reports Previous 7 Days & 9 & 45 & 0 & 823 \\
\hline Opening Day & .02 & & 0 & 1 \\
\hline $\operatorname{Rain}^{\#}$ & .03 & & 0 & 1 \\
\hline Average Temp Fahrenheit ${ }^{\#}$ & 78 & 9.1 & 44 & 91 \\
\hline Social Distancing (May 6-11 2009) & .02 & & 0 & 1 \\
\hline \multicolumn{5}{|l|}{2009 Only* } \\
\hline Attendance & 3406 & 2418 & 0 & 16000 \\
\hline State Influenza Reports Previous 7 Days & 49 & 97 & 0 & 823 \\
\hline Moderate Social Distancing (May 6-11 2009) & .05 & & 0 & 1 \\
\hline Attendance with Moderate Social Distancing & 3225 & 1503 & 341 & 5772 \\
\hline Attendance 2009 No Social Distancing & 3562 & 2154 & 300 & 12306 \\
\hline Attendance May 6 -11, Not 2009 & 4159 & 3449 & 600 & 21101 \\
\hline
\end{tabular}

* The H1N1 outbreak occurred in 2009 and we have no influenza data for other years \# weather data was collected from 2008-2010

Table 2. Influenza like Symptoms (ILI) Reports in State Previous 3-5 Days and Attendance 2009*

$\begin{array}{lccc}\text { Number of Cases } & \text { Attendance } & \text { Mean ILI } & \text { Obs } \\ 0 & 3834 & 0 & 84 \\ 1-4 & 4432 & 2.4 & 158 \\ 5-13 & 3634 & 8.8 & 145 \\ 14-65 & 3216 & 31.9 & 155 \\ 66+ & 2696 & 206.9 & 149 \\ 0-1 & 4132 & 0 & 128 \\ 2-3 & 4601 & 3 & 80 \\ 3-4 & 3778 & 5 & 84 \\ 5-13 & 3526 & 10 & 95 \\ 14-27 & 3212 & 19 & 75 \\ 28-65 & 3164 & 43 & 77 \\ 65-153 & 3315 & 102 & 76 \\ 154+ & 2151 & 306 & 76\end{array}$

*excludes opening day and only includes 2009 data the year of the outbreak

To demonstrate the relationship between influenza and attendance, Figure 1 plots the natural $\log$ of attendance and the $\log$ of the number of ILI reports. ${ }^{1}$ For the first three groups, additional ILI reports within the group seem to have no effect on attendance. However, for the fourth group with the highest number of ILI there seems to be a negative and linear relationship between the two. Returning to Table 2 where the number of cases is broken into eight groups, we

\footnotetext{
${ }^{1}$ We add one to the number of ILI reports, so the $\log$ is defined for states with zero reports.
} 
see a reduction in attendance after at least 4 cases only in the highest level of ILI reports, and there is a large drop in attendance.

Figure 1. Log Attendance and Influenza like Illness Reports by Influenza Group

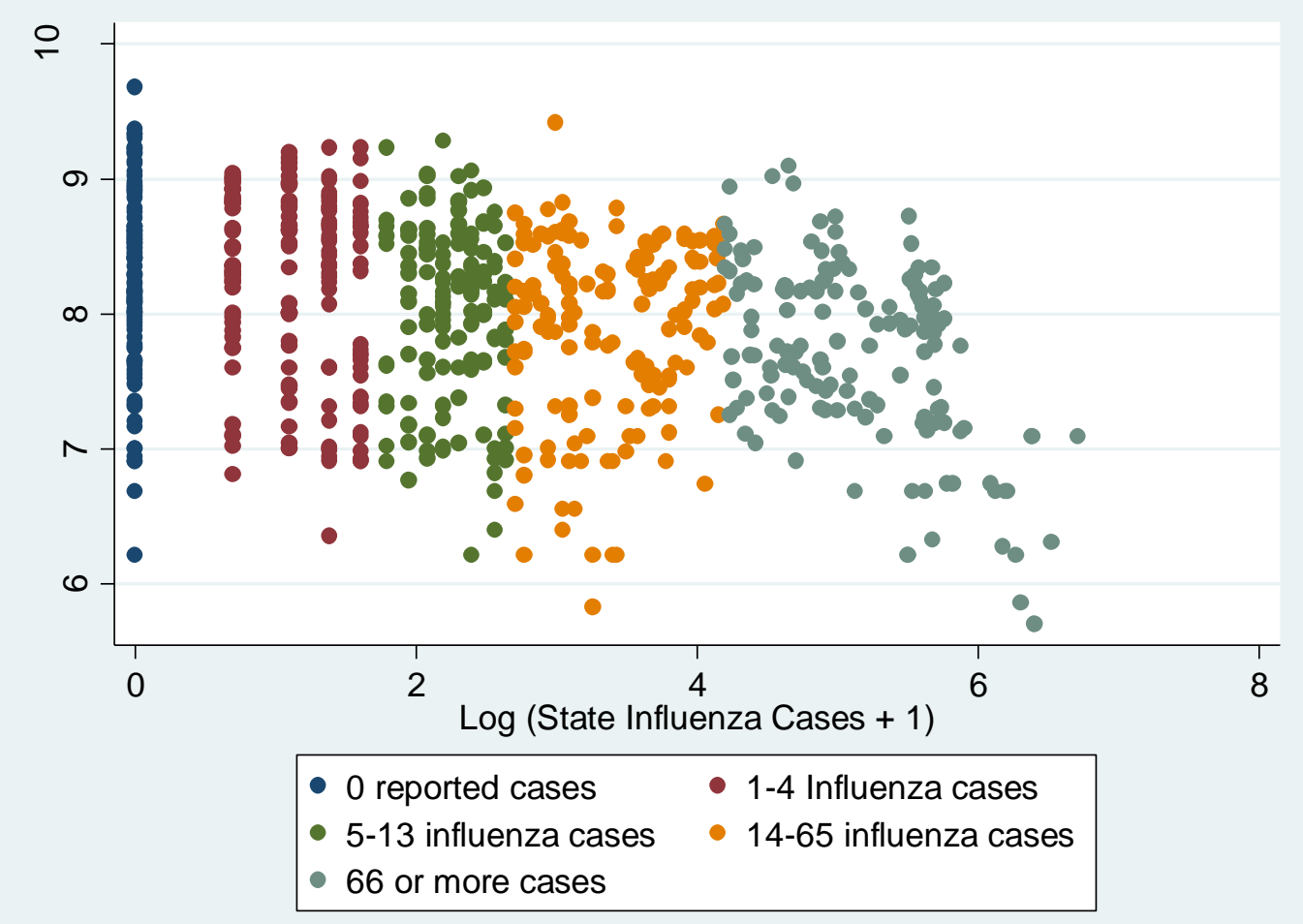

In addition to reports of influenza, we added variables that influence attendance and are exogenous to the influenza outbreak. These descriptive statistics are reported in Table 1. First, we controlled for the first game of the season (opening day) when attendance is substantially larger. Attendance on opening day averages 9,400 compared to 4,000 for all other games. Second, we controlled for the opponent, as the schedule was set before the outbreak. Butler (2002) shows in an analysis of US Major League Baseball that an opponent's quality can heavily influence attendance.

We also controlled for weather using data from Weatherunderground.com of the nearest airport weather station. We only have weather data from the years 2008-2010, which limits the sample size. Since all the Mexican baseball parks are located outdoors, the weather can influence attendance as shown by works on US MLB. Butler (2002) and Lemke (2010) find that both rain and cold weather decrease attendance. Weather during the Mexican baseball season is excellent with only $3 \%$ of days having at least $1 \mathrm{~cm}$ of rain. The average temperature is 78 degrees and $70 \%$ of games are played between 55 and 85 degrees. 


\section{Econometric Model}

The econometric model is used to test two hypotheses related to the relationship between influenza and attendance at baseball games. The first hypothesis is that an increase in the number of influenza like illness will decrease attendance. The second is that social distancing measures that discourage gatherings will also reduce attendance. The goal of the regression analysis is to test these hypotheses, while controlling for other factors that will likely influence attendance. A team fixed effects regression is used to control for time invariant factors related to attendance. The regression is shown below (equation 1) estimates the natural log of attendance (lny) for team " $\mathrm{i}$ " in state " $\mathrm{s}$ " in time " $\mathrm{t}$ " based on the number of influenza-like illness reports $(Z)$ in the team's home state "s", if moderate social distancing measures were in place and team fixed effects $\left(\sum_{i=1}^{i=15} \gamma_{i}\right.$ Team $\left._{i}\right)$. The error term or the variation in attendance not explained by control factors is represented by "e". In the analysis above, it does not appear that ILI reports are linearly related to attendance (see figure 1). Therefore, we create a series of binary dummies denoted with an uppercase where $\mathrm{Z}_{\mathrm{k}}=1$ if the ILI reports is within the group " $k$ ". We ran two separate analyses changing the number of groups from four to eight to examine non-linearities. A closer look at Figure 1 suggests when the data is divided into five groups that there is a linear negative relationship between ILI and attendance only in the groups with the most reports of ILI. To test this relationship, we add in an interaction term that $\ln \left(z_{\text {ist }}\right) * Z_{4 s t}$. Where $z_{\text {ist }}$ is the number of influenza cases and $\mathrm{Z}_{4 \mathrm{st}}=1$ if the numbers of ILI reports is in the highest ILI group.

As mentioned above the Mexican government enforced social distancing measures that canceled games from April $27^{\text {th }}$ to May $5^{\text {th }}$ of 2009 we therefore have no observations during this period. Moderate social distancing measures continued until May 11, though games were played May 6 - May 11, 2009. To estimate the effects on attendance of the moderate social distancing measures for the period where games were played but other social events were canceled, a binary variable $\mathrm{D}=1$ was entered if the game took place from May 6 to 11 of 2009.

$$
\begin{aligned}
& \ln \left(y_{i s t}\right)=\beta_{0}+\sum_{k=1}^{k=\# \text { of Quantile-1 }} \alpha_{k} Z_{i s t}+\delta_{1} D_{t}+\sum_{i=1}^{i=15} \gamma_{i} \text { Team }_{i}+\mathrm{e}(1) \\
& \ln \left(y_{\text {ist }}\right)=\beta_{0}+\sum_{k=1}^{k=4} \alpha_{k} Z_{\text {ist }}+\beta_{1} \ln \left(z_{\text {ist }}\right) * Z_{4 s t}+\delta_{1} D_{t}+\sum_{i=1}^{i=15} \gamma_{i} \text { Team }_{i}+\mathrm{e}(2)
\end{aligned}
$$

Several variables are also included to control for factors beyond those of the two key hypotheses. The first is Opening Day, which equals one on the first game of the season. Opponent fixed effects are included to control for visiting fans. We also include time fixed effects including binary dummy variables for each year, month, and day of the week. ${ }^{2}$

For roughly half the sample we also have weather data from the nearest airport. To control for weather, we use a binary variable $(R A I N=1)$ if the state

\footnotetext{
${ }^{2}$ H1N1 infections are only observed in 2009, so we estimate equation 3 for all years with year fixed effects and for only 2009 without year fixed effects, the results are consistent.
} 
level weather station reported at least $1 \mathrm{~cm}$ of rain on the day of the game. To control for temperature, we create four binary variables for different temperature ranges (85-76, 75-66, 66-55; and below 55 degrees Fahrenheit), which $=1$ if the daily temperature average falls in the range. Finally, all analyses cluster the error terms at the team level. The full regression is below in equation 3 .

$$
\begin{aligned}
& \ln \left(y_{\text {ist }}\right)=\beta_{0}+\sum_{k=1}^{k=\# \text { of Group }-1} \alpha_{k} Z_{\text {ist }}+\delta_{1} D_{t}+\sum_{i=1}^{i=15} \gamma_{i} \text { Team }_{i} \\
& +\beta_{1} \text { OpeningDay }+\sum_{j=1}^{j=15} \gamma_{J} \text { OpposingTeam }_{i} \\
& +\sum_{\substack{w=1 \\
M=7}}^{w=6} \gamma_{w} \text { Day of } \text { Wee }_{w t} \\
& +\sum_{M=4}^{M=7} \theta_{M} \text { Month }_{\text {tm }}+\sum_{\text {year }=\text { min year }}^{\substack{\text { year }=\text { max } \\
\text { year }}} \delta_{\text {year }} \text { Year }+\beta_{7} \text { Rain } \\
& +\sum_{k=1}^{k=4} \delta_{k} \text { TempCat }+e(3)
\end{aligned}
$$

\section{Results}

The results of the empirical analysis, reported in Table 3, support both hypotheses. Across all models we see evidence to support our first hypothesis that influenza is negatively related to attendance. The point estimates show that high levels of ILI roughly reduce attendance by $20 \%$. The final three models are suggestive of additional marginal impacts on attendance for additional cases, but only at the highest level of ILI reports (greater than 66 cases). We also find evidence to support our second hypothesis that social distancing measures reduce attendance. In all models we all see that attendance fell during May $6^{\text {th }}$ to $11^{\text {th }} 2009$ when the government enacted moderate social distancing measures.

In Table 3 we see no difference between the lowest ILI group and the omitted category (no ILI reported). For the second and third highest ILI reports, attendance is reduced roughly $18 \%$ (significant at the 10\% level) and $25 \%$ at the highest ILI reports. The second model adds weather data, which reduces the sample size by half, but has little impact on the results. The third and fourth models further reduce the sample to just 2009, the year of the outbreak. This strengthens the statistical significance and increases the point estimates.

The final models include an interaction between a log of the number of ILI cases and a binary indicator of those states in the fourth group with the most ILI. As predicted by Figure 1, we find a greater negative effect of ILI on attendance when the rate of ILI is higher. Using the coefficient from model 6 , a 
one standard deviation increase in ILI for the fourth group reduces attendance an additional $3.7 \%(.313 * .12)$.

In Table 4 we further breakdown the number of ILI cases into 8 groups with 0 or 1 cases being the omitted comparison group. In general, the results are consistent with those from the previous table in that more ILI cases do not seem to affect attendance until the very highest number of cases is reached. One issue with this model was multi-colinearity as the month controls were often correlated with the ILI categories. When the controls for the month are removed the statistical significance and sign is more consistent with the expected result.

Across all models in Tables 3 and 4, and consistent with our second hypothesis, moderate social distancing reduces attendance. From May 6-11, 2009 the Mexican government discouraged public gatherings as part of moderate social distancing measures. The range of coefficients suggest during this time attendance was reduced between roughly 15-25\%.Baseball games, however, could resume with fans in attendance. In all models except one the statistical significance is at the $1 \%$ and in the other one at the $5 \%$ level.

Examining the other variables in Tables 3 and 4, not surprisingly, opening day had a huge effect on attendance with a coefficient of roughly 1 indicating opening day having twice the average attendance of a typical game. The time controls for fixed effects are particularly interesting when examining the year controls. They are suggestive of 2009 being a down year for attendance and 2010 being even worse, which is likely reflective of the difficulties in the economy at that time. With 2005 being the omitted year in model 1, it appears attendance was relatively unchanged between 2005 and 2006. However, it was $19 \%$ and $35 \%$ higher in 2007 and 2008 than in 2005. In the year of the outbreak the point estimates suggest attendance between 2007 and 2008 levels controlling for other factors, with attendance returning to 2005 levels in 2010. In Model 2, which omits 2008, we see attendance dropping 17\% and 42\% in 2009 and 2010 in comparison to 2008 . 
Table 3. Natural Log of Attendance and 4 Groups of H1N1 Cases\#

\begin{tabular}{|c|c|c|c|c|c|c|c|c|}
\hline & 1 & 2 & 3 & 4 & 5 & 6 & 7 & 8 \\
\hline \multirow[t]{2}{*}{ 1-4 ILI cases } & 0.021 & 0.058 & -0.022 & -0.012 & NA & 0.120 & -0.007 & NA \\
\hline & $(0.085)$ & $(0.087)$ & $(0.075)$ & $(0.071)$ & & (0.109) & $(0.071)$ & \\
\hline \multirow[t]{2}{*}{ 5-13 ILI cases } & $-0.181^{*}$ & $-0.161^{*}$ & $-0.191^{* *}$ & $-0.181^{*}$ & $-0.171^{* * *}$ & -0.126 & $-0.180^{*}$ & $-0.176^{* * *}$ \\
\hline & $(0.096)$ & $(0.084)$ & $(0.086)$ & $(0.091)$ & $(0.057)$ & $(0.095)$ & $(0.090)$ & $(0.056)$ \\
\hline \multirow[t]{2}{*}{ 14-65 ILI cases } & $-0.184^{*}$ & $-0.223^{* *}$ & $-0.225^{*}$ & $-0.206^{*}$ & $-0.186^{* *}$ & $-0.195 * *$ & $-0.199 *$ & $-0.182^{* *}$ \\
\hline & $(0.096)$ & $(0.101)$ & $(0.107)$ & $(0.107)$ & $(0.071)$ & $(0.086)$ & $(0.107)$ & $(0.072)$ \\
\hline \multirow[t]{2}{*}{66 or ILI cases } & $-0.252^{*}$ & $-0.194^{*}$ & $-0.322^{* * *}$ & $-0.305^{* * *}$ & $-0.278^{* * *}$ & $1.464^{*}$ & $0.710^{* *}$ & $0.710^{* * *}$ \\
\hline & $(0.130)$ & $(0.109)$ & $(0.087)$ & $(0.100)$ & $(0.083)$ & $(0.746)$ & $(0.251)$ & $(0.200)$ \\
\hline \multirow[t]{2}{*}{66 or More ILI cases* In(\# of Cases) } & & & & & & $-0.313^{*}$ & $-0.200 * * *$ & $-0.197^{* * *}$ \\
\hline & & & & & & $(0.156)$ & $(0.045)$ & $(0.037)$ \\
\hline \multirow[t]{2}{*}{ Social Distancing Measures } & $-0.228 * * *$ & $-0.148^{* *}$ & $-0.203^{* * *}$ & $-0.193^{* * *}$ & $-0.206^{* * *}$ & $-0.166^{* *}$ & $-0.226^{* * *}$ & $-0.241^{* * *}$ \\
\hline & $(0.059)$ & $(0.056)$ & $(0.064)$ & $(0.062)$ & $(0.065)$ & $(0.061)$ & $(0.060)$ & $(0.062)$ \\
\hline \multirow[t]{2}{*}{ Opening Day } & $1.034^{* * *}$ & $0.988^{* * *}$ & $1.053^{* * *}$ & $1.077^{* * *}$ & NA & $0.991^{* * *}$ & $1.078^{* * *}$ & NA \\
\hline & $(0.087)$ & $(0.088)$ & $(0.131)$ & $(0.140)$ & & $(0.079)$ & $(0.140)$ & \\
\hline \multirow[t]{2}{*}{ Monday } & $-0.299 * * *$ & -0.149 & -0.109 & -0.101 & -0.110 & -0.165 & -0.112 & -0.119 \\
\hline & $(0.089)$ & $(0.154)$ & $(0.095)$ & $(0.097)$ & $(0.086)$ & $(0.182)$ & $(0.103)$ & (0.098) \\
\hline \multirow[t]{2}{*}{ Tuesday } & $-0.117^{* *}$ & -0.101 & -0.107 & -0.091 & -0.088 & -0.098 & -0.097 & -0.095 \\
\hline & $(0.050)$ & $(0.060)$ & $(0.081)$ & $(0.076)$ & $(0.065)$ & $(0.060)$ & $(0.078)$ & $(0.067)$ \\
\hline \multirow[t]{2}{*}{ Wednesday } & $-0.170^{* * *}$ & $-0.122^{*}$ & $-0.148^{*}$ & $-0.146^{*}$ & $-0.130^{*}$ & $-0.117^{*}$ & $-0.151^{*}$ & $-0.135^{*}$ \\
\hline & $(0.050)$ & $(0.060)$ & $(0.078)$ & $(0.078)$ & $(0.065)$ & $(0.061)$ & $(0.080)$ & $(0.067)$ \\
\hline \multirow[t]{2}{*}{ Thursday } & -0.079 & -0.031 & -0.021 & -0.015 & 0.014 & -0.037 & -0.023 & 0.006 \\
\hline & $(0.048)$ & $(0.062)$ & $(0.080)$ & $(0.079)$ & $(0.077)$ & $(0.062)$ & $(0.078)$ & $(0.076)$ \\
\hline \multirow[t]{2}{*}{ Friday } & $-0.081^{* *}$ & -0.058 & -0.096 & -0.091 & -0.107 & -0.057 & -0.095 & $-0.112^{*}$ \\
\hline & $(0.036)$ & $(0.050)$ & $(0.074)$ & $(0.073)$ & $(0.065)$ & $(0.049)$ & $(0.071)$ & $(0.064)$ \\
\hline \multirow[t]{2}{*}{ Saturday } & -0.035 & -0.028 & -0.049 & -0.047 & -0.056 & -0.032 & -0.048 & -0.059 \\
\hline & $(0.026)$ & $(0.041)$ & $(0.073)$ & $(0.073)$ & $(0.065)$ & $(0.044)$ & $(0.075)$ & $(0.066)$ \\
\hline \multirow[t]{2}{*}{ Year 2006} & -0.012 & & & & & & & \\
\hline & $(0.117)$ & & & & & & & \\
\hline \multirow[t]{2}{*}{ Year 2007} & $0.188^{*}$ & & & & & & & \\
\hline & $(0.098)$ & & & & & & & \\
\hline \multirow[t]{2}{*}{ Year 2008} & $0.344^{* *}$ & & & & & & & \\
\hline & $(0.138)$ & & & & & & & \\
\hline \multirow[t]{2}{*}{ Year 2009} & 0.235 & $-0.171^{* *}$ & & & & & & \\
\hline & (0.149) & $(0.059)$ & & & & & & \\
\hline Year 2010 & -0.015 & $-0.417^{* * *}$ & & & & & & \\
\hline & $(0.153)$ & $(0.082)$ & & & & & & \\
\hline Rain on Game Day & & $-0.094^{*}$ & & 0.009 & 0.003 & $-0.104^{*}$ & 0.031 & 0.026 \\
\hline & & $(0.052)$ & & $(0.089)$ & $(0.096)$ & $(0.049)$ & $(0.077)$ & $(0.084)$ \\
\hline Temp 84-75 Degrees & & 0.073 & & -0.022 & -0.012 & $0.105^{* *}$ & -0.018 & -0.006 \\
\hline & & $(0.046)$ & & $(0.045)$ & $(0.037)$ & $(0.048)$ & $(0.047)$ & $(0.040)$ \\
\hline Temp 74-65 Degrees & & $0.119 *$ & & 0.115 & 0.101 & $0.129 *$ & 0.115 & 0.098 \\
\hline & & $(0.063)$ & & $(0.089)$ & $(0.082)$ & $(0.069)$ & $(0.091)$ & $(0.083)$ \\
\hline Temp 64-55 degrees & & 0.146 & & 0.181 & 0.230 & $0.180^{*}$ & 0.183 & 0.230 \\
\hline & & $(0.087)$ & & $(0.137)$ & $(0.148)$ & $(0.085)$ & $(0.138)$ & $(0.150)$ \\
\hline Below 55 & & 0.225 & & $0.255^{* *}$ & $0.370^{* *}$ & $0.254^{*}$ & $0.260 * *$ & $0.376^{* *}$ \\
\hline & & $(0.132)$ & & $(0.117)$ & $(0.150)$ & $(0.119)$ & $(0.118)$ & $(0.152)$ \\
\hline Constant & $7.965^{* * *}$ & $8.190^{* * *}$ & $8.166 * * *$ & $8.153^{* * *}$ & $8.173^{* * *}$ & $7.953^{* * *}$ & $8.162^{* * *}$ & $8.189 * * *$ \\
\hline & $(0.103)$ & $(0.116)$ & $(0.119)$ & $(0.128)$ & $(0.110)$ & $(0.130)$ & $(0.130)$ & $(0.110)$ \\
\hline Weather & No & Yes & No & Yes & Yes & Yes & Yes & Yes \\
\hline Obs with 0 ILI Cases & Yes & Yes & Yes & Yes & No & Yes & Yes & No \\
\hline Year(s) & $2005-2010$ & $2008-2010$ & 2009 & 2009 & 2009 & 2009 & 2009 & 2009 \\
\hline Observations & 4,657 & 2,025 & 706 & 684 & 593 & 2,025 & 684 & 593 \\
\hline R-squared & 0.223 & 0.335 & 0.330 & 0.343 & 0.239 & 0.244 & 0.354 & 0.254 \\
\hline Robust standard errors in parenthese & & & & & & & & \\
\hline$* * * p<0.01,{ }^{* *} p<0.05, * p<0.1$ & & & & & & & & \\
\hline
\end{tabular}

\#includes team and opponent fixed effects, which are omitted to improve readability. 
Table 4. Natural Log of Attendance and 8 Groups of H1N1 Cases\#

\begin{tabular}{|c|c|c|c|c|c|c|}
\hline VARIABLES & & & & & & \\
\hline \multicolumn{7}{|c|}{ Number of Influenza Like Symptoms Reported } \\
\hline \multirow[t]{2}{*}{$2-3$} & 0.096 & 0.017 & 0.080 & 0.034 & 0.039 & -0.042 \\
\hline & $(0.075)$ & $(0.085)$ & $(0.083)$ & $(0.089)$ & $(0.079)$ & $(0.092)$ \\
\hline \multirow[t]{2}{*}{$4-7$} & -0.069 & -0.163 & -0.093 & -0.155 & -0.043 & -0.140 \\
\hline & (0.102) & $(0.128)$ & $(0.113)$ & $(0.117)$ & $(0.069)$ & $(0.111)$ \\
\hline \multirow[t]{2}{*}{$8-13$} & $-0.177^{*}$ & $-0.225^{* *}$ & $-0.184^{* *}$ & $-0.228 * *$ & $-0.141^{*}$ & $-0.223 * *$ \\
\hline & $(0.086)$ & $(0.096)$ & $(0.070)$ & $(0.078)$ & $(0.066)$ & $(0.086)$ \\
\hline \multirow[t]{2}{*}{$14-27$} & -0.126 & $-0.264^{*}$ & $-0.199 *$ & $-0.286^{*}$ & -0.100 & $-0.240^{*}$ \\
\hline & $(0.127)$ & $(0.142)$ & $(0.111)$ & $(0.134)$ & $(0.074)$ & $(0.134)$ \\
\hline \multirow[t]{2}{*}{$28-65$} & -0.054 & $-0.168^{* *}$ & $-0.210^{* *}$ & $-0.262^{* *}$ & $-0.169 * *$ & $-0.232^{* *}$ \\
\hline & $(0.053)$ & $(0.080)$ & $(0.078)$ & $(0.090)$ & $(0.060)$ & $(0.081)$ \\
\hline \multirow[t]{2}{*}{$65-153$} & 0.086 & -0.082 & -0.020 & -0.089 & -0.130 & $-0.241^{* * *}$ \\
\hline & $(0.094)$ & $(0.095)$ & $(0.065)$ & $(0.073)$ & $(0.080)$ & $(0.076)$ \\
\hline \multirow[t]{2}{*}{154 or more } & -0.265 & $-0.464^{*}$ & -0.281 & $-0.385^{*}$ & $-0.292^{* *}$ & $-0.444^{* * *}$ \\
\hline & $(0.217)$ & $(0.224)$ & (0.196) & $(0.189)$ & $(0.123)$ & $(0.108)$ \\
\hline \multirow[t]{2}{*}{ Social Distancin Measures } & $-0.300 * * *$ & $-0.270 * * *$ & $-0.209 * * *$ & $-0.179 * * *$ & $-0.209 * *$ & $-0.221 * * *$ \\
\hline & $(0.058)$ & $(0.062)$ & $(0.054)$ & $(0.060)$ & $(0.077)$ & $(0.063)$ \\
\hline \multirow[t]{2}{*}{ Opening Day } & $0.945^{* * *}$ & $1.030^{* * *}$ & $1.009 * * *$ & $0.975^{* * *}$ & $1.039 * * *$ & $1.042^{* * *}$ \\
\hline & $(0.086)$ & $(0.088)$ & $(0.101)$ & $(0.092)$ & $(0.206)$ & $(0.131)$ \\
\hline \multirow[t]{2}{*}{ Constant } & $8.053^{* * *}$ & $7.966^{* * *}$ & $8.265^{* * *}$ & $8.190 * * *$ & $8.226^{* * *}$ & $8.189 * * *$ \\
\hline & $(0.106)$ & $(0.103)$ & $(0.127)$ & $(0.117)$ & $(0.249)$ & $(0.118)$ \\
\hline Observations & 4,657 & 4,657 & 2,025 & 2,025 & 684 & 706 \\
\hline R-squared & 0.268 & 0.227 & 0.363 & 0.342 & 0.388 & 0.338 \\
\hline Controls for weather & No & No & Yes & Yes & Yes & Yes \\
\hline Controls for month & Yes & No & Yes & No & Yes & No \\
\hline Years Covered & $2005-2010$ & $2005-2010$ & $2008-2010$ & $2008-2010$ & 2009 & 2009 \\
\hline \multicolumn{7}{|c|}{ Robust standard errors in parentheses } \\
\hline${ }^{* * *} p<0.01,{ }^{* *} p<0.05,{ }^{*} p<0.1$ & & & & & & \\
\hline
\end{tabular}

\section{Conclusion}

Pandemics like the H1N1 outbreak in Mexico in 2009 have the potential to severely inhibit economic activity, particularly social gathering. We first provide an estimate of the cost of the outbreak to a specific type of gathering. We also provide an estimate to the economic costs of social distancing measures that discourage attendance. Attendance is negatively related to the spread of the outbreak as predicted in our first hypothesis. We also find that moderate social distancing measures that discouraged public gatherings reduced attendance by roughly $20 \%$. Our contribution is to provide a building block to estimate the cost of the social distancing measures. 
The first clear shortcoming of this study is the potential external validity. It is unknown if baseball attendance is representative of how people may make decisions to gathering for other economic activities, such as concerts, restaurants, or shopping. However, as we note, other studies examine tourists, which are not representative of local populations. This study does provide, as far as we can tell, the first estimate of the relationship between an outbreak and gathering for a local population.

Ideally, we would have liked to model the relationship between games and future reports of influenza-like illness - that is, test if games themselves increase the spread of H1N1. We found no evidence to support this, however we believe this may be an issue of statistical power. We attempted this by regressing the number of ILI reports on the number of games or a binary indicator if there was a game. We lagged the days of potential game between 3 days and 7 days. One issue is that, relative to Mexico's population of 122 million, the number of people attending any of the 8 games on any single day is small (roughly 32,000 ), roughly 1 per 3,300 people in Mexico. Thus, it is not unexpected that we do not find a relationship. Future research may focus on outbreaks that occur where the percentage of the population attending events is higher, such as MLB where attendance is a factor of 10 higher, but the US population is less than 3 times higher. Another limitation is we have no comparison group for the social distancing measures. Ideally, social distancing measures would have been used in some, but not all states.

A vaccine has been invented and distributed to combat the spread of H1N1 since the outbreak in 2009. However, H1N1 is on the rise again in Latin American countries. In Mexico there were 524 deaths and 9,164 cases of H1N1 in 2016 (TelesurTV 2016). In Brazil in 2016 there have been twice as many deaths and the number of H1N1 cases is the highest in the country since the 2009 outbreak (Plus55 2016). This is all despite vaccination rates being above $95 \%$ in Brazil. Given H1N1's resurgence and the uncertainty behind the spread of the Zika virus, the potential for consideration of social distancing measures to stop the spread of a virus seems likely in the near future.

\section{Acknowledgment}

The author would like to thank Gerardo Chowell- Puente for sharing the data on influenza reports and comments on previous drafts. I would also like to thank Robert Gitter for comments as well as participants at the North American Sports Economics Association sessions at the Western Economics Association Meetings, seminar participants at Loyola and Towson University. 


\section{References}

Butler MR (2002) Interleague play and baseball attendance. Journal of Sports Economics 3(4): 320-334.

Coburn BJ, Wagner BG, Blower S (2009)Modeling influenza epidemics and pandemics: insights into the future of swine flu (H1N1). BMC Med 7(30).

Chowell G, Echevarría-Zuno S, Viboud C, Simonsen L, Tamerius J, et al. 2011. Characterizing the Epidemiology of the 2009 Influenza A/H1N1 Pandemic in Mexico. PLoS Med 8(5). https://doi.org/10.1371/journal.pmed.1000436.

Dixon PB, Rimmer MT, Verikios G (2009) "Effects on the U.S. Economy of a Serious H1N1 Epidemic: Analysis with the USAGE Model" Non-published Research Reports, paper 16.

Hens N, Ayele GM, Goeyvaerts N, Aerts M, Mossong J, et al. (2009) Estimating the impact of school closure on social mixing behaviour and the transmission of close contact infections in eight European countries. BMC Infect Dis 9: 187.

Kuo H, Chang C, Huang B, Chen C, McAleer, M (2009) Estimating the Impact of Avian Flu on International Tourism Demand Using Panel Data. Tourism Economics 15(3): 501-511.

Lemke R J, Leonard M, Tlhokwane K(2010) Estimating attendance at Major League Baseball games for the 2007 season. Journal of Sports Economics 11(3): 316-348.

Markowitz S, Nesson E, Robinson J(2010) Are Pink Slips Better Than Flu Shots? The Effects of Employment on Influenza Rates. NBER working paper 15796.

Moltz D (2009) "Flu and Football Season" Inside Higher Ed. Retrieved from https:// www.insidehighered.com/news/2009/08/25/h1n1.

Plus55 (2016) Brazil Experiences Worst H1n1 Flu Outbreak since 2009 Pandemic. Retrieved from http://plus55.com/culture/2016/06/brazil-experiences-worst-h1n1flu-outbreak-since-2009-pandemic. [Accessed 29 June 2016].

Rassy D, Smith RD(2013) The economic impact of H1N1 on Mexico's tourist and pork sectors. Health economics 22(7): 824-834.

Rosselló J, Santana-Gallego M, Awan W (2017) Infectious disease risk and international tourism demand. Health policy and planning 32(4): 538-548.

Stoecker C, Sanders NJ, Barreca A(2016) Success Is something to sneeze at: Influenza mortality in cities that participate in the super bowl. American Journal of Health Economics.

Sun LH (2016, May 29) 150 experts say Olympics must be moved or postponed because of Zika. Washington Post.

Telesurtv (2016) Swine Flu Outbreak: Bolivia Launches Anti-H1N1 Campaign. Retrieved from http://www.telesurtv.net/english/news/Swine-Flu-Outbreak-Bolivia-LaunchesAnti-H1N1-Campaign--20160627-0003.html. [Accessed 29 June 2016].

USA Today (2003) "Blue Jays sell out after offering \$1 tickets". Retrieved from http:// usatoday30.usatoday.com/sports/baseball/al/bluejays/2003-04-29-sars-sellout_x.htm. [Accessed 11 November 2014]

Wu JT, Cowling BJ, Lau EH, Ip DK, Ho LM,et al (2010) School closure and mitigation of pandemic (H1N1) 2009, Hong Kong. Emerg Infect Dis 16: 538-541. 
